\title{
Using phytoestrogens as aprophylaxis against irregular uterine bleeding possibly occurring while using Depot-medroxyprogesterone acetate (DMPA) as a contraceptive method
}

\author{
Iman Ali Abd El Fattah*
}

Department of Obstetrics \& Gynecology, Faculty of Medicine, Shatby Maternaty Hospital, Alexandria University, Alexandria, Egypt

Received: 9 September 2014

Accepted: 19 September 2014

\section{*Correspondence:}

Dr. Iman Ali Abd El Fattah,

E-mail: eman0eman0eman7@Gmail.com

Copyright: $\odot$ the author(s), publisher and licensee Medip Academy. This is an open-access article distributed under the terms of the Creative Commons Attribution Non-Commercial License, which permits unrestricted non-commercial use, distribution, and reproduction in any medium, provided the original work is properly cited.

\begin{abstract}
Background: High-dose progestogen - only contraceptives, such as injectable DMPA, inhibit follicular development and prevent ovulation as their primary mechanism of action. Inhibition of ovarian function during DMPA use causes the endometrium to become thin and atrophic. These changes in the endometrium in the first months of use results in irregular or unpredictable bleeding or spotting, or rarely, heavy or continuous bleeding .Phytoestrogens are plant-derived xeno-estrogens functioning as the primary female sex hormone not generated within the endocrine system but consumed by eating phytoestrogenic plants. Also called "dietary estrogens", they are a diverse group of naturally occurring non-steroidal plant compounds that, because of their structural similarity with estradiol (17- $\beta$-estradiol), have the ability to cause estrogenic or/and antiestrogenic effects through binding to estrogen receptors. The management of women who present with unscheduled bleeding while using hormonal contraception is challenging. Although numerous research studies have attempted to investigate preventative and therapeutic treatments for women using hormonal contraception with unscheduled bleeding, none are of sufficient quality to guide management in clinical practice usefully. In this study we are testing the ability of phytoestrogens to prevent the break-through bleeding that can occur during the use of depot medroxy-progesterone acetate as a contraceptive.
\end{abstract}

Methods: Fifty cases of depot provera users are selected and divided into two groups: group I: 25 cases will start the injection alone. Group II: 25 cases will start the injection with using regular daily phytoestrogen. All cases are followed up for the first six months after the injection for the occurrence of break-through bleeding, and the endometrial thickness using the trans-vaginal ultrasonography.

Results: There was a statistically significant difference in the endometrial thickness between group receiving depot provera alone and the group receiving both depot provera and phytoestrogen.

Conclusions: We can use phytoestrogens to decrease DMPA-associated vaginal bleeding.

Keywords: Contraception, Depot-medroxy progesterone acetate, Estrogen receptors, Phytoestrogens, Breakthrough bleeding, Endometrial thickness

\section{INTRODUCTION}

High-dose progestogen - only contraceptives, such as injectable DMPA, inhibit follicular development and prevent ovulation as their primary mechanism of action. ${ }^{1,2}$ The progestogen decreases the pulse frequency of gonadotropin-releasing hormone $(\mathrm{GnRH})$ release by the hypothalamus, which decreases the release of Follicle-Stimulating Hormone (FSH) and Luteinizing Hormone (LH) by the anterior pituitary. Decreased levels 
of FSH inhibit follicular development, preventing an increase in estradiol levels. Progestogen negative feedback and the lack of estrogen positive feedback on LH release prevent a LH surge. Inhibition of follicular development and the absence of a $\mathrm{LH}$ surge prevent ovulation. $^{3,4}$

A secondary mechanism of action of all progestogencontaining contraceptives is inhibition of sperm penetration by changes in the cervical mucus. ${ }^{5}$

Inhibition of ovarian function during DMPA use causes the endometrium to become thin and atrophic. These changes in the endometrium in the first months of use results in irregular or unpredictable bleeding or spotting, or rarely, heavy or continuous bleeding.

Phytoestrogens are plant-derived xenoestrogens functioning as the primary female sex hormone not generated within the endocrine system but consumed by eating phytoestrogenic plants. Also called "dietary estrogens", they are a diverse group of naturally occurring nonsteroidal plant compounds that, because of their structural similarity with estradiol (17- $\beta$-estradiol), have the ability to cause estrogenic or/and antiestrogenic effects. $^{6}$

Phytoestrogens exert their effects primarily through binding to Estrogen Receptors (ER). ${ }^{7}$ There are two variants of the estrogen receptor, alpha (ER- $\alpha)$ and beta (ER- $\beta$ ) and many phytoestrogens display somewhat higher affinity for ER- $\beta$ compared to ER- $\alpha{ }^{7}$

In addition to interaction with ERs, phytoestrogens may also modulate the concentration of endogenous estrogens by binding or inactivating some enzymes, and may affect the bioavailability of sex hormones by depressing or stimulating the synthesis of Sex Hormone-Binding Globulin (SHBG). ${ }^{8}$

\section{Aim of the work}

In this study we are testing the ability of phytoestrogens to prevent the break-through bleeding that can occur during the use of depot medroxyprogesterone acetate as a contraceptive.

\section{METHODS}

Fifty cases of depot provera users are selected and divided into two groups:

Group I: 25 cases will start the injection alone.

Group II: 25 cases will start the injection with using regular daily phytoestrogen in the form of dry extract preparation of Cimicifugaracemosa rhizome (Klimadynon, Bionorica, Germany) at a dose of 120 mglday.
All cases are examined clinically and investigated before the injection, then they are followed up for the first six months after the injection for the occurrence of breakthrough bleeding, and the endometrial thickness using the trans-vaginal ultrasonography.

The endometrium was measured in the long-axis or sagittal plane. The measurement is of the thickest echogenic area from one basal endometrial interface across the endometrial canal to the other basal endometrium not including the hypo-echoic myometrium. ${ }^{9}$ To be considered atrophic, the endometrial thickness should measure less than $4-5 \mathrm{~mm}$ on a transvaginal ultrasound scan. ${ }^{10}$

\section{RESULTS}

A prospective study was conducted in Alexandria, Egypt.

DMPA users were counseled to participate. Women who agreed to participate were randomly allocated into two groups:

Group I: 25 cases will start the injection alone.

Group II: 25 cases will start the injection with regular daily use of phytoestrogen in the form of dry extract preparation of Cimicifugaracemosa rhizome (Klimadynon, Bionorica, Germany) at a dose of 120 mglday.

All participants were asked to report bleeding and spotting days in a menstrual diary. All participants were followed for 6 months after treatment as regards the occurrence of break through bleeding and changes in endometrium thickness using the vaginal ultrasonography. The results of the present study are presented as comparison between the two main groups.

\section{Age}

Table 1: Age in the study and control groups: demographic data the two studied groups.

\begin{tabular}{|lll|} 
& Group I & Group II \\
\hline Min & 32 & 33 \\
\hline Max & 40 & 39 \\
\hline Mean \pm SD & $35.66 \pm 2.626$ & $35.96 \pm 1.979$ \\
\hline T-test & 1.117 & \\
\hline P value & 0.265 & \\
\hline
\end{tabular}

P: P value

NS: not statistically significant

There was no statistically significant difference in age between the two groups $(\mathrm{t}=1.117, \mathrm{P}=0.265)$

This assures that the age was matched among the studied groups and homogenously distributed. 


\section{BMI}

Table 2: Comparison between the two studied groups regarding the body mass index.

\begin{tabular}{|lllll|}
\hline & \multicolumn{2}{l}{ Group I } & \multicolumn{2}{c|}{ Group II } \\
& No. & \% & No. & \% \\
\hline Normal weight & 5 & 20.0 & 3 & 12.0 \\
\hline Over weight & 14 & 56.0 & 12 & 48.0 \\
\hline Obese & 6 & 24.0 & 10 & 40.0 \\
\hline $\mathrm{X}^{2}$ & 1.22 & & \\
\hline $\mathrm{P}$ & 0.365 & & \\
\hline
\end{tabular}

$\mathrm{X}_{\mathrm{KW}}^{2}$ : Chi square test of Kruskal-Wallis test,

NS: not statistically significant

*Statistically significant $(\mathrm{P}<0.05)$

There was no statistically significant difference in the BMI between the two groups $(\mathrm{P}=0.365)$

\section{Endometrial thickness}

Table 3: Comparison between the two studied groups regarding endometrial thickness before and after treatment.

\begin{tabular}{|c|c|c|c|}
\hline & Group I & Group II & $\begin{array}{l}\text { t-test } \\
\text { P value }\end{array}$ \\
\hline \multicolumn{3}{|c|}{ Before treatment } & \multirow{4}{*}{$\begin{array}{l}1.05 \\
0.311\end{array}$} \\
\hline Min & 4.00 & 3.00 & \\
\hline $\operatorname{Max}$ & 12.00 & 11.00 & \\
\hline Mean \pm SD & $7.33 \pm 4.17$ & $7.89 \pm 5.14$ & \\
\hline $\begin{array}{l}\text { After } 6 \\
\text { months }\end{array}$ & $\begin{array}{l}\text { After depot } \\
\text { provera alone }\end{array}$ & $\begin{array}{l}\text { After depot provera } \\
+ \text { phytoestrogen }\end{array}$ & \\
\hline Min & 5.0 & 9.0 & \multirow{3}{*}{$\begin{array}{l}2.69 \\
0.01 *\end{array}$} \\
\hline Max & 12.0 & 14.0 & \\
\hline Mean \pm SD & $8.1 \pm 2.3$ & $13.1 \pm 2.65$ & \\
\hline $\mathbf{T}$ & 1.02 & 2.22 & \\
\hline $\mathbf{P}$ & 1.06 & $0.011^{*}$ & \\
\hline
\end{tabular}

There was a statistically significant difference in the endometrial thickness between group receiving depot provera alone and the group receiving both depot provera and phytoestrogen $(\mathrm{P}=0.011)$

\section{Break through bleeding}

Table 4: Comparison between the two studied groups regarding the incidence break through bleeding.

\begin{tabular}{|lllll|}
\hline Break through & \multicolumn{2}{c|}{ Group I } & \multicolumn{2}{c|}{ Group II } \\
bleeding & No. & \% & No. & \% \\
\hline Yes & 13 & 52.0 & 3 & 12.0 \\
\hline No & 12 & 48.0 & 22 & 88.0 \\
\hline $\mathbf{X}^{\mathbf{2}}$ & 9.59 & & \\
\hline P & $0.0001^{*}$ & & \\
\hline
\end{tabular}

There was a statistically significant difference in the occurrence of break-through bleeding between group receiving depot provera alone and the group receiving both depot provera and phytoestrogen $(\mathrm{P}=0.0001)$

\section{DISCUSSION}

During a normal menstrual cycle the endometrium is exposed to circulating sex steroids. It is the sequential exposure of the endometrium to the natural steroids, estradiol and progesterone, that leads to the characteristic histological features. ${ }^{11}$

Estradiol exposure during the follicular phase is responsible for endometrial proliferation. Exposure to progesterone in the luteal phase results in secretory differentiation. Progesterone is anti-estrogenic and inhibits endometrial growth and glandular differentiation. It is the withdrawal of estrogen and progesterone, in the absence of pregnancy, that triggers the onset of menstrual bleeding. ${ }^{12}$

Exogenous administration of sex steroids, in the form of hormonal contraception, will dramatically influence endometrial histology. The endometrial response to hormonal contraception will reflect circulating sex hormone concentrations plus the dose and formulation of steroid delivery, the route of delivery of the steroid, and the timing and duration of administration. ${ }^{12,13}$

The exact mechanisms of unscheduled bleeding associated with hormonal contraception have yet to be explained. The evidence to date implicates superficial blood vessel fragility within the endometrium as a consistent problematic feature.

In addition, local changes in endometrial steroid response, structural integrity, tissue perfusion and local angiogenic factors are likely to contribute. ${ }^{(13)}$ Since there are no established long-term interventions available to manage unscheduled bleeding, a greater understanding of the mechanisms involved is required.

One trial ${ }^{14}$ in a Cochrane review ${ }^{16}$ evaluated the effect of estrogen on bleeding in women using depot medroxyprogesterone acetate (DMPA). This randomized trial included 278 women using DMPA with irregular bleeding who were randomised to receive either EE (50 $\mu \mathrm{g})$, estrogen sulphate $(2.5 \mathrm{mg})$ or placebo daily for 14 days. Although this trial of therapeutic treatment was designed to identify both short- and long-term effects, there was a high rate of discontinuation $(40 \%$ in each group) thus giving a major risk of bias. Only EE was effective in stopping bleeding in the 14 days of treatment [relative risk (RR) 0.26 , 95\% Confidence Interval (CI) 0.11-0.60]. In the 3 months following treatment, however, any ongoing beneficial effects of $50 \mu \mathrm{g} \mathrm{EE}$ on bleeding was minimal (RR 0.06, 95\% CI 0.00-1.00).

A Cochrane review ${ }^{16}$ included trials using estrogen (oral diethylstilbestrol, oral quinesterol or a $17 \beta$ estradiol transdermal patch) as a preventative treatment for women starting DMPA. The individual trial results were difficult to interpret within the meta-analysis and discontinuation rates were high. 
In our trial using phytoestrogens, bleeding did not occur in $88 \%$ of users and only $12 \%$ of users complained of bleeding which was minimal and no cases of discontinuation was reported.

One trial investigated the use of a non-steroidal antiinflammatory drug (NSAID) (mefenamic acid) for bleeding in women using DMPA. ${ }^{15}$ Women had to have at least 8 days bleeding or spotting prior to participating in the trial and to be bleeding on the day of recruitment. This small, randomised, double-blind, placebo-controlled trial found that mefenamic acid (500 mg twice daily for 5 days) was effective in reducing a bleeding episode. ${ }^{14,15}$ The usual regimen for mefenamic acid is $500 \mathrm{mg}$ three times daily but there are no studies investigating this dose and its effect on bleeding. Around $70 \%$ of women had stopped bleeding within 7 days of starting mefenamic acid (compared to $40 \%$ with placebo; $\mathrm{P}<0.05$ ). There was no significant difference in the mean bleed-free interval in the longer term (28 days following treatment).

A randomised controlled trial showed that mifepristone (50 $\mathrm{mg}$ as a single dose on day 14 and every 2 weeks for six cycles) reported a significant reduction in breakthrough bleeding compared to women given placebo. $^{17}$

More recent evidence of short-term benefit of mefenamic acid use in already established bleeding has been published. ${ }^{15}$ but there is no evidence in literature on its use as a prophylaxis.

There is no direct evidence on the use of a low-dose $(<50$ $\mu \mathrm{g}) \mathrm{COC}$ to treat unscheduled bleeding in women using progestogen-only injectable contraception. Despite this the UKSPR supports the use of EE (given as a COC) as a short-term treatment option in women with light or heavy bleeding with progestogen-only injectable contraception. No recommendation was given regarding the use of an NSAID in the UKSPR20 and World Health Organization selected practice recommendations for contraceptive use. $^{18}$

Based on limited evidence, the CEU recommend that as a first-line option a COC may be used by women using progestogen-only injectable contraception with unscheduled bleeding if there are no contraindications to use of estrogen. The COC can be used for up to 3 months while continuing with DMPA (unlicensed use). The COC can be taken in the usual cyclic manner (with a withdrawal bleeding) or continuously without a pill-free interval. Based on more recent evidence ${ }^{15}$ for women who have a contraindication to $\mathrm{COC}$ use then mefenamic acid (500 $\mathrm{mg}$ twice or three times daily for 5 days) may be considered to attenuate a bleeding episode but there is no evidence that this approach has an effect on bleeding patterns in the longer term. A small randomised controlled trial ${ }^{17}$ suggested that there is some evidence that a cox-2 inhibitor (valdecoxib) is effective in the treatment of uterine bleeding with DMPA, however the use of cox-2 inhibitors for this purpose is unlicensed in some countries.

In our study we succeeded to avoid the occurrence of breakthrough in depot-provera users. Accordingly, we recommend the use of phytoestrogens as a prophylaxis.

\section{CONCLUSION}

There as decreasing DMPA-associated vaginal bleeding through the use of phytoestrogens.

\section{Key message}

Depot-medroxy progesterone acetate used as contraceptive may cause breakthrough bleeding due to endometrial atrophy caused by estrogen deficiency, Phytoestrogens may prevent this bleeding due to their estrogenic effect on the endometrium.

Funding: No funding sources Conflict of interest: None declared

Ethical approval: The study was approved by the institutional ethics committee

\section{REFERENCES}

1. Glasier Anna. Contraception. In: DeGroot Leslie J, Jameson J. Larry, eds. Endocrinology. 5th ed. Philadelphia: Elsevier Saunders; 2006: 2993-3003.

2. Loose Davis S, Stancel George M. Estrogens and progestins. In: Brunton Laurence L, Lazo John S, Parker Keith L, eds. Goodman \& Gilman's The Pharmacological Basis of Therapeutics. 11th ed. New York: McGraw-Hill; 2006: 1541-1571.

3. Hatcher Robert A. Depo-provera injections, implants, and progestin - only pills (Minipills). In: Hatcher Robert A, Trussell James, Stewart Felicia H, Nelson Anita L, Cates Jr Willard, Guest Felicia, et al., eds. Contraceptive Technology. 18th ed. New York: Ardent Media; 2004: 461-494.

4. Speroff Leon, Darney Philip D. Injectable contraception. In: Speroff Leon, Darney Philip D, eds. A Clinical Guide for Contraception. 4th ed. Philadelphia: Lippincott Williams \& Wilkins; 2005: 201-220.

5. Rivera R, Yacobson I, Grimes D. The mechanism of action of hormonal contraceptives and intrauterine contraceptive devices. Am J Obstet Gynecol. 1999;181(5 Pt 1):1263-9.

6. Yildiz Fatih. Phytoestrogens in Functional Foods. In: Yildiz Fatih, eds. A Book. 2nd ed. UK: Taylor \& Francis Ltd; 2005: 3-5, 210-211.

7. Turner JV, Agatonovic-Kustrin S, Glass BD. Molecular aspects of phytoestrogen selective binding at estrogen receptors. J Pharm Sci. 2007 Aug;96(8):1879-85.

8. Johnston I. Phytoestrogens. In: Johnston I, eds. Phytochem Functional Foods. 1st ed. UK: CRC Press Inc; 2003: 66-68. 
9. Sahdev A. Imaging the endometrium in postmenopausal bleeding. BMJ. 2007;334(7594):635-6.

10. Dubinsky TJ. Value of sonography in the diagnosis of abnormal vaginal bleeding. J Clin Ultrasound. 2004;32(7):348-53.

11. Noyes RW, Hertig AT, Rock J. Dating the endometrial biopsy. Am J Obstet Gynecol. 1975;122:262-3.

12. Jabbour HN, Kelly RW, Fraser HM, Critchley HOD. Endocrine regulation of menstruation. Endocr Rev. 2006;27:17-46.

13. Smith OP, Critchley HO. Progestogen only contraception and endometrial break through bleeding. Angiogenesis. 2005;8:117-26.

14. Said S. Clinical evaluation of the therapeutic effectiveness of ethinyl oestradiol and oestrone sulphate on prolonged bleeding in women using depot medroxyprogesterone acetate for contraception. Hum Reprod. 1996;11:1-13.

15. Tantiwattanakul P, Taneepanichskul S. Effect of mefenamic acid on controlling irregular uterine bleeding in DMPA users. Contraception. 2004;70:277-9.
16. Abdel-Aleem H, d'Arcangues C, Vogelsong K, Gulmezoglu AM. Treatment of vaginal bleeding irregularities induced by progestin only contraceptives. Cochrane Database Syst Rev. 2007;4:CD003449.

17. Jain JK, Nicosia AF, Nucatola DL, Lu JJ, Kuo LJ, Felix JC. Mifepristone for the prevention of breakthrough bleeding in new starters of depomedroxyprogesterone acetate. Steroids. 2003;68:1115-9. Nathirojanakun P, Taneepanichskul S, Sappakitkumjorn N. Efficacy of a selective cox-2 inhibitor for controlling irregular uterine bleeding in DMPA use. Contraception. 2006;73:584-7.

18. World Health Organization. Selected practice recommendations for contraceptive use. In: WHO, eds. WHO Guide. 2nd ed. Geneva: World Health Organization; 2005: 1-174.

DOI: $10.5455 / 2320-1770$. ijrcog20141219

Cite this article as: Fattah IAA. Using

phytoestrogens as aprophylaxis against irregular uterine bleeding possibly occurring while using Depot-medroxyprogesterone acetate (DMPA) as a contraceptive method. Int J Reprod Contracept Obstet Gynecol 2014;3:977-81. 